\title{
Sensitisation to Blattella germanica among adults with asthma in Yaounde, Cameroon: a cross- sectional study
}

Eric Walter Pefura-Yone ${ }^{1,2^{*}}$, André Pascal Kengne ${ }^{3}$, Emmanuel Afane-Ze $e^{1,2}$ and Christopher Kuaban ${ }^{1,2,4}$

\begin{abstract}
Background: German cockroach or Blattella germanica is commonly found in homes across the inter-tropical region. The contribution of sensitisation to Blattella germanica in people with asthma in sub-Saharan Africa has not received attention. The aim of this study was to assess the prevalence and investigate the predicting factors of sensitisation to Blattella germanica in patients with asthma in Yaounde, Cameroon.
\end{abstract}

Methods: This was a cross-sectional study conducted between January 2012 and June 2013. All patients (aged 15 years and above) with asthma, receiving care at the Yaounde Jamot Hospital and the CEDIMER medical practice during the study period and who had received a prick skin testing for perennial aeroallergens were included in the study.

Results: The final sample comprised 184 patients including 123 (66.8\%) women. The median age (25th-75th percentiles) was 38 (24-54) years. Prick skin test for Blattella germanica was positive in 47 (25.5\%) patients. Sensitisation to Blattella germanica was associated with a sensitisation to mite in 41 (87.2\%) patients, a sensitisation to Alternaria in 18 (38.3\%) patients, and a sensitisation to cat or dog dander in 7 (14.9\%) patients. Independent predicting factors of a sensitisation to Blattella germanica were the sensitisation to Blomia tropicalis [adjusted odd ratio ( $95 \%$ confidence interval) 4.10 (1.67-10.04), $p=0.002$ ] and sensitisation to Alternaria [3.67 (1.53-7.46), $p=0.003$.

Conclusions: Sensitisation to Blattella germanica is present in about a quarter of adult patients with asthma in Yaounde. Sensitisation to Alternaria and Blomia tropicalis appears to be a powerful predicting factor of sensitisation to Blattella germanica in this setting.

Keywords: Asthma, Blattella, Allergy, Aeroallergens, Africa

\section{Introduction}

Cockroaches have been identified as one of the major indoor allergens inducing respiratory allergies [1]. Cockroaches are cosmopolitan and are found in large number in warm and humid dwellings, particularly in urban setting [2]. Among the 3,500 known cockroach species, five species (the German cockroach or Blattella germanica, the American or Periplaneta americana, the Oriental or Blatta orientalis, the smokey brown or Periplaneta fuliginosa, and the brown-banded or Supella longipalpis) are involved in the sensitisation of atopic patients [1-3].

\footnotetext{
* Correspondence: pefura2002@yahoo.fr

'Department of Internal Medicine and Subspecialties, Faculty of Medicine and Biomedical Sciences, University of Yaounde I, Yaounde, Cameroon ${ }^{2}$ Pneumology service, Yaounde Jamot Hospital, P.O Box: 4021, Yaounde, Cameroon

Full list of author information is available at the end of the article
}

The prevalence of the sensitisation to these species varies across regions worldwide and ranges between 30 to $60 \%$ in patients with asthma $[2,4,5]$. Blattella germanica is one of the cockroach species commonly found in homes in Cameroon and in sub-Saharan Africa (SSA) at large [6]. The profile of the sensitisation to Blattella germanica in patients with respiratory allergy (asthma or rhinitis) has been largely described in most regions around the world. However, we are not aware of studies on frequency and predicting factors of the sensitisation to Blattella germanica in patients with asthma in subSaharan Africa at large and in Cameroon in particular. Therefore, the aim of this study was to assess the prevalence and investigate the determinants of sensitisation to Blattella germanica in adult asthmatic individuals in Yaounde, Cameroon. 


\section{Material and methods Study setting and participants}

This study was approved by the ethics committee of the Yaounde Jamot Hospital. It was a cross-sectional study of 18 months duration between January 2012 and June 2013. The study was conducted at the outpatient sections of the Yaounde Jamot Hospital and the private medical practice CEDIMER, both based in Yaounde which is the Capital city of Cameroon. All patients aged 15 years and above, followed for asthma at both institutions during the recruitment period, were invited to take part in the study. Diagnosis of asthma used the Global Initiative for Asthma (GINA) criteria, and was conducted by an experienced chest specialist physician (EWPY). Confirmation of the diagnosis of asthma was based on the GINA criteria [7] and included the presence of episodes of cough, dyspnoea and wheezing associated with reversible airflow obstruction, or non-specific bronchial hyper-responsiveness $[7,8]$. Patients in whom allergologic skin tests were not conducted were excluded from the study.

\section{Methods}

The following data were collected from all patients: demographic and clinical data including age (in years), sex, ethnicity, duration of asthma, family history of asthma, history of other allergic disease (rhinitis, conjunctivitis, atopic dermatitis) and smoking habits. A diagnosis of rhinitis was based on the following nasal symptoms: colorless rhinorrhoea, nasal congestion, sneezing and itching. The severity of rhinitis was assessed following the classification of the Allergic Rhinitis and its Impact on Asthma (ARIA) group. Rhinitis was considered as persisting if the above symptoms have been present for more than four weeks and for a minimal of four consecutive weeks, otherwise, it was considered as intermittent [9]. The same criteria were applied for intermittent and persisting conjunctivitis and in the presence of symptoms suggesting an ocular allergy including itching, flush, lacrimation and eyelid swelling [10]. The United Kingdom Working Party clinical criteria were applied for the diagnosis of atopic dermatitis [11].

Control of asthma was assessed with the use of the asthma control questionnaire (ACQ) [12,13]. Asthma was considered to be insufficiently controlled during the preceding week in the presence of an ACQ score $\geq 1$ $[12,13]$. The basal (in the absence of any exacerbation) forced expiratory volume in 1 second (FEV1) was recorded for all participants. Basal FEV1 was calculated as the ratio of the measured FEV1 and theoretical FEV1 of each patient. The theoretical FEV1 was estimated with the relevant 2012 Global Lung Initiative equations [14].

Prick tests were performed using the allergenic extracts of Stallergenes Laboratory (Anthony, France). The following perennial aeroallergens were tested: mites
(Dermatophagoïdes pteronyssinus, Dermatophagoïdes farinae and Blomia tropicalis), fungi (Alternaria alternata), Blattella germanica, cat dander and dog dander. A $1 \%$ histamine solution was used as positive control, while a phenolic glycerosaline solution was used as negative control. A prick-test was considered positive in the presence of a papule with a diameter greater than $3 \mathrm{~mm}$ as compared with that of the negative control, or $50 \%$ the diameter of the positive control.

\section{Statistical analysis}

Data analysis used the Statistical Package for Social Sciences (SPSS) v.17 (SPSS Inc., Chicago, USA). Results are presented as median (interquartile range) or count (percentages). The Chi-square test or Fisher exact test were used to compare proportions and the Mann-Whitney $\mathrm{U}$ test used to compare quantitative variables. Logistic regressions models were used to investigate the determinants of sensitisation to Blattella germanica. Candidate predictors included demographic and clinical variables (sex, age, ethnicity, age at the diagnosis of asthma, family history of asthma, history of rhinitis or atopic dermatitis, smoking, asthma control and basal FEV1), and allergologic variables (sensitisation to mites, sensitisation to Alternaria, sensitisation to animal dander). Associated factors with a p-value $<0.10$ in univariable analyses were entered altogether in the same multivariable models and the significant one retained as independent associated factors. A p-value $<0.05$ was used to characterise statistically significant results.

\section{Results}

\section{General characteristic of the study population}

Of the 190 asthmatic adults received in the outpatient departments during the study period, 6 (3.2\%) were excluded for missing skin prick testing. Therefore, the final sample comprised 184 patients, of whom 123 (66.8\%) were women and $51(33.2 \%)$ were men. Their median age (25th-75th percentiles) was $38(24-54)$ years. The median age at the onset of asthma was 22 (12-38) years, and $19(10.9 \%)$ and $63(39.4 \%)$ patients had intermittent and persistent rhinitis respectively. In the week preceding inclusion their enrolment, 97 (57.7\%) patients had well-controlled asthma and the median FEV1 was $88.1 \%$ (73.5-99.3) (Table 1).

\section{Prevalence of sensitisation to Blattella germanica}

The prevalence (95\% confidence interval) of sensitisation to Blattella germanica was $25.5 \%$ (19.2-31.8\%). Sensitisation to Blattella germanica was associated with a sensitisation to mite in $41(87.2 \%)$ patients, a sensitisation to Alternaria in 18 (38.3\%) patients, and a sensitisation to cat or dog dander in 7 (14.9\%) patients. 
Table 1 Demographic and clinical characteristics of asthmatic adults in Yaounde according to the sensitisation to Blattella germanica (BG)

\begin{tabular}{|c|c|c|c|c|}
\hline Characteristics & $\begin{array}{l}\text { Total sample } \\
\mathrm{n}=184(\%)\end{array}$ & $\begin{array}{l}\text { Sensitisation to BG } \\
n=47(\%)\end{array}$ & $\begin{array}{l}\text { No sensitisation to } B G \\
n=137(\%)\end{array}$ & $p$ \\
\hline \multicolumn{5}{|l|}{ Sex } \\
\hline Men & $51(33.2)$ & $15(31.9)$ & $46(33.6)$ & \multirow[t]{2}{*}{0.835} \\
\hline Women & $123(66.8)$ & $32(68.81)$ & $91(66.4)$ & \\
\hline Median age, years, (25th-75th percentiles) & $38(24-54)$ & $32(24-50)$ & $41(23.5-56)$ & 0.119 \\
\hline \multicolumn{5}{|l|}{ Ethnic groups } \\
\hline Semi-bantou & $130(71.4)$ & $32(69.6)$ & $98(72.1)$ & Reference \\
\hline Bantou & $37(20.3)$ & $10(21.7)$ & $27(19.9)$ & 0.765 \\
\hline Fulani/Sudanese & $15(8.2)$ & $4(8.7)$ & $11(8.1)$ & 0.862 \\
\hline Others & $2(1.1)$ & $1(2.1)$ & $1(0.7)$ & 0.439 \\
\hline $\begin{array}{l}\text { Median age at the onset of asthma, years } \\
\text { (25th-75th percentiles) }\end{array}$ & $24(14-40)$ & $23(16-39)$ & $24(13-41.5)$ & 0.720 \\
\hline \multicolumn{5}{|l|}{ Rhinitis } \\
\hline None & $93(50.5)$ & $22(46.8)$ & $71(51.8)$ & Reference \\
\hline Intermittent rhinitis & $25(13.8)$ & $7(14.9)$ & $18(13.1)$ & 0.654 \\
\hline Persistent rhinitis & $66(35.9)$ & $18(38.3)$ & $48(35.0)$ & 0.604 \\
\hline \multicolumn{5}{|l|}{ Atopic dermatitis } \\
\hline Yes & $4(2.2)$ & $3(6.4)$ & $1(0.7)$ & \multirow[t]{2}{*}{0.052} \\
\hline No & $180(97.8)$ & $44(93.6)$ & $136(99.3)$ & \\
\hline \multicolumn{5}{|l|}{ Active smoking } \\
\hline Non-smoker & $157(98.1)$ & $42(97.7)$ & $115(98.3)$ & Reference \\
\hline Smoker/ex-smoker & $3(1.6)$ & $1(2.1)$ & $2(1.5)$ & 0.612 \\
\hline Second hand smoker & $4(2.2)$ & $2(4.3)$ & $2(1.5)$ & 0.301 \\
\hline \multicolumn{5}{|l|}{ Family history of asthma } \\
\hline Yes & $33(17.9)$ & $7(14.9)$ & $26(19.0)$ & \multirow[t]{2}{*}{0.529} \\
\hline No & $151(82.1)$ & $40(85.1)$ & $111(81.0)$ & \\
\hline \multicolumn{5}{|l|}{ Asthma control } \\
\hline Well controlled & $97(57.7)$ & $25(55.6)$ & $72(58.5)$ & \multirow[t]{2}{*}{0.729} \\
\hline Not well controlled & $71(42.3)$ & $20(44.4)$ & $51(41.5)$ & \\
\hline FEV1, \%, median, (25th-75th percentiles) & $88.1(73.5-99.3)$ & $88,1(77-99.5)$ & $88.1(70.5-99.3)$ & 0.225 \\
\hline
\end{tabular}

FEV1, forced expiratory volume in $1 \mathrm{~s}$.

\section{Predicting factors of sensitisation to Blattella germanica}

There was no difference between patients sensitised and those who were not sensitised to Blattella germanica with regard to sex, age, age at clinical onset of asthma and family history of asthma. There was a non-significant high prevalence of history of atopic dermatitis in patients sensitised to Blattella germanica compared to those not sensitised $(6.4 \%$ vs $0.7 \%, \mathrm{p}=0.052)$ (Table 1$)$.

Univariable and multivariable associations between sensitisation to Blattella germanica and other non-pollinic related aeroallergens are shown in Table 2 and Table 3. The independent predicting factors of sensitisation to Blattella germanica were: sensitisation to Blomia tropicalis [mutually adjusted odd ratio (95\% confidence interval) 4.10
(1.67-10.04), $\mathrm{p}=0.002]$ and sensitisation to Alternaria [3.67 (1.53-8.81), $\mathrm{p}=0.004]$.

\section{Discussion}

The main findings from this study conducted in a developing country of sub-Saharan Africa are the following: 1) about a quarter of asthmatic adults in urban setting are sensitised to Blattella germanica; 2) sensitisation to Blattella germanica is unrelated to the known age at the onset of asthma; and 3) sensitisation to Blattella germanica is associated with a sensitisation to Blomia tropicalis and Alternaria.

The prevalence of sensitisation to Blattella germanica found in our study is comparable to the $23 \%$ rate found 
Table 2 Univariable association between sensitisation to other aeroallergens and sensitisation to Blattella germanica (BG)

\begin{tabular}{|c|c|c|c|c|c|}
\hline Characteristics & $\begin{array}{l}\text { Total } \\
\mathrm{n}=184(\%)\end{array}$ & $\begin{array}{l}\text { Sensitisation to BG } \\
n=47(\%)\end{array}$ & $\begin{array}{l}\text { No sensitisation to BG } \\
n=137(\%)\end{array}$ & $\begin{array}{l}\text { Crude } \\
\text { OR }(95 \% \mathrm{Cl})\end{array}$ & $p$ \\
\hline Sensitisation to Dermatophagoïdes pteronyssinus & $93(50.5)$ & $33(70.2)$ & $60(43.8)$ & $3.03(1.49-6.16)$ & 0.002 \\
\hline Sensitisation to Dermatophagoïdes farinae & $88(47.8)$ & $31(66.0)$ & $57(41.6)$ & $2.72(1.36-5.44)$ & 0.004 \\
\hline Sensitisation to Blomia tropicalis & $85(46.2)$ & $36(76.6)$ & $49(35.8)$ & $5.88(2.75-12.57)$ & $<0.001$ \\
\hline Sensitisation to Alternaria & $32(17.4)$ & $18(38.3)$ & $14(10.2)$ & $5.43(2.43-12.22)$ & $<0.001$ \\
\hline Sensitisation to cat dander & $13(7.1)$ & $6(12.8)$ & $7(5.1)$ & $2.72(0.86-8.55)$ & 0.099 \\
\hline Sensitisation to dog dander & $7(3.8)$ & $2(4.3)$ & $5(3.6)$ & $1.17(0.22-6.26)$ & 1.000 \\
\hline
\end{tabular}

$\mathrm{OR}$, odds ratio.

among asthmatic patients in China [15]. The prevalence of sensitisation to cockroach in studies among atopic patients has been found to be $17.4 \%$ in Portugal [16], 20.2\% in Turkish [17], 36.8\% in the United States [18] and 55\% in Brazil [19]. Sensitisation to Blattella germanica was not associated with the known age at the onset of asthma in our study. Therefore, the onset of asthma either in the childhood, adolescent or adult age does not seem to affect the sensitisation to Blattella germanica. In a study conducted by Sun et al. in the general population in China, sensitisation to cockroach was found to be more frequent among adults than in children [15].

In this study, sensitisation to Blattella germanica occurred in the context of multiple sensitisations with sensitisation to Blomia tropicalis and Alternaria. Sensitisation to Blomia tropicalis was independently associated with sensitisation to Blattella germanica in our study. Indeed, $76.6 \%$ of patients sensitised to Blattella germanica were also sensitised to Blomia tropicalis as opposed to only $35.8 \%$ for patients not sensitised to Blattella germanica. This association is explained at least in part by the crossreactivity between mite and cockroaches via tropomyosin, but may also reflect true multiple sensitisations [2,19,20]. In the study by Julia-Serda et al., sensitisation to cockroach was also found to be associated with a sensitisation to Blomia tropicalis [21].

We also found an association between sensitisation to Blattella germanica and sensitisation to Alternaria. We found no existing report describing multiple sensitisation linking Blattella germanica and Alternaria. The two species are very distant phylogenetically, and the association we found appears not to be related to a crossreaction, but rather to multiple sensitisations in atopic patients. Confirmations of our findings in other settings are needed. Furthermore, employing recombinant major allergens of the two aeroallergens may help to elucidate this association.

The use of prick-test alone to diagnose allergenic sensitisation is a limitation of the current study. Indeed, concomitant measurement of specific immunoglobulin $\mathrm{E}$ could have diagnosed other sensitisations among patients with cutaneous hyporeactivity. The two recruitment centres for this study have a primary focus on the management of the adult's conditions, which precluded the inclusion of children in our study. It is therefore possible that finding from the current study may not be generalizable to the paediatric population with asthma in the same setting. Furthermore, we have not included non-asthmatic participants in the study; therefore, the association between asthma and cockroach atopy could not be assessed in this study.

\section{Conclusions}

In conclusion, sensitisation to Blattella germanica is frequent among adult asthmatic patients in Yaounde. This sensitisation appear to be unrelated to the known age of onset of asthma, but rather associated with sensitisation to Alternaria and to Blomia tropicalis; a finding that requires confirmation and further investigation.

Table 3 Multivariable adjusted predicting factors of the sensitisation to Blattella germanica

\begin{tabular}{lll}
\hline Predicting factor & Adjusted odds ratio (95\% confidence interval) & $\mathbf{p}$ \\
\hline Sensitisation to Dermatophagoïdes pteronyssinus & $1.09(0.38-3,11)$ & 0.868 \\
Sensitisation to Dermatophagoïdes farinae & $1.21(0.44-3.36)$ & 0.715 \\
Sensitisation to Blomia tropicalis & $4.10(1.67-10.04)$ & 0.002 \\
Sensitisation to Alternaria & $3.67(1.53-8.81)$ & 0.004 \\
Sensitisation to cat dander & $2.07(0.58-7.46)$ & 0.266 \\
\hline
\end{tabular}




\section{Consent}

Written informed consent was obtained from the patients or dear tutors for the publication of this report and any accompanying images.

\section{Abbreviations}

ACQ: Asthma control questionnaire; FEV1: Forced expiratory volume in 1 second; GINA: Global Initiative for Asthma; SPSS: Statistical Package for Social Sciences; SSA: Sub-Saharan Africa.

\section{Competing interests}

The authors declare that they have no competing interests.

\section{Authors' contribution}

EWPY conceived the study, collected data, co-analysed the data and drafted of the manuscript; APK contributed to study designed, data analysis, drafting and critical revision of the manuscript; EAZ supervised the data collection and critically revised the manuscript; CK supervised the data collection and critically revised the manuscript. All authors read and approved the final manuscript.

\section{Author details}

'Department of Internal Medicine and Subspecialties, Faculty of Medicine and Biomedical Sciences, University of Yaounde I, Yaounde, Cameroon. ${ }^{2}$ Pneumology service, Yaounde Jamot Hospital, P.O Box: 4021, Yaounde, Cameroon. ${ }^{3}$ South African Medical Research Council \& University of Cape Town, Cape Town, South Africa. ${ }^{4}$ Faculty of health sciences, University of Bamenda, Bamenda, Cameroon.

Received: 14 August 2013 Accepted: 29 July 2014

Published: 19 August 2014

\section{References}

1. Sohn MH, Kim KE: The cockroach and allergic diseases. Allergy Asthma Immunol Res 2012, 4:264-269.

2. Wu CH, Lee MF: Molecular characteristics of cockroach allergens. Cell Mol Immunol 2005, 2:177-180.

3. Sookrung N, Chaicumpa W: A revisit to cockroach allergens. Asian Pac J Allergy Immunol 2010, 28:95-106.

4. Leung R, Lam CW, Ho A, Chan JK, Choy D, Lai CK: Allergic sensitisation to common environmental allergens in adult asthmatics in Hong Kong. Hong Kong Med J 1997, 3:211-217.

5. Al-Tamemi SH, Al-Shidhani AN, Al-Abri RK, Jothi B, Al-Rawas OA, Al-Riyami BM: The pattern of sensitisation to inhalant allergens in omani patients with asthma, allergic rhinitis and rhinoconjunctivitis. Sultan Qaboos Univ Med J 2008, 8:319-324.

6. Patterson R, Koehler P: Peridomestic cockroach suppression with hydramethylnon bait. J Agric Entomol 1989, 6:37-42.

7. GINA: Global strategy for asthma management and prevention 2012 updated. In Global Initiative for Asthma (GINA). 2012. http://www.ginasthma.org/.

8. Miller MR, Hankinson J, Brusasco V, Burgos F, Casaburi R, Coates A, Crapo R, Enright $P$, van der Grinten $C P$, Gustafsson $P$, Jensen $R$, Johnson DC, Maclntyre N, McKay R, Navajas D, Pedersen OF, Pellegrino R, Viegi G, Wanger J; ATS/ERS Task Force: Standardisation of spirometry. Eur Respir J 2005, 26:319-338.

9. Bousquet J, Schunemann HJ, Samolinski B, Demoly P, Baena-Cagnani CE, Bachert C, Bonini S, Boulet LP, Bousquet PJ, Brozek JL, Canonica GW, Casale TB, Cruz AA, Fokkens WJ, Fonseca JA, van Wijk RG, Grouse L, Haahtela T, Khaltaev N, Kuna P, Lockey RF, Lodrup Carlsen KC, Mullol J, Naclerio R, O'Hehir RE, Ohta K, Palkonen S, Papadopoulos NG, Passalacqua G, Pawankar R: Allergic Rhinitis and its Impact on Asthma (ARIA): achievements in 10 years and future needs. J Allergy Clin Immunol 2012, 130:1049-1062.

10. Leonardi A, Bogacka E, Fauquert JL, Kowalski ML, Groblewska A, JedrzejczakCzechowicz M, Doan S, Marmouz F, Demoly P, Delgado L: Ocular allergy: recognizing and diagnosing hypersensitivity disorders of the ocular surface. Allergy 2012, 67:1327-1337.

11. Williams HC, Burney PG, Pembroke AC, Hay RJ: The U.K. Working Party's Diagnostic Criteria for Atopic Dermatitis. III. Independent hospital validation. Br J Dermatol 1994, 131:406-416.
12. Juniper EF, O'Byrne PM, Guyatt GH, Ferrie PJ, King DR: Development and validation of a questionnaire to measure asthma control. Eur Respir J 1999, 14:902-907.

13. Juniper EF, Bousquet J, Abetz L, Bateman ED: Identifying 'well-controlled' and 'not well-controlled' asthma using the Asthma Control Questionnaire. Respir Med 2006, 100:616-621.

14. Quanjer PH, Stanojevic S, Cole TJ, Baur X, Hall GL, Culver BH, Enright PL, Hankinson JL, Ip MS, Zheng J, Stocks J; ERS Global Lung Function Initiative: Multi-ethnic reference values for spirometry for the 3-95-yr age range: the global lung function 2012 equations. Eur Respir J 2012, 40:1324-1343.

15. Sun BQ, Lai XX, Gjesing B, Spangfort MD, Zhong NS: Prevalence of sensitivity to cockroach allergens and lgE cross-reactivity between cockroach and house dust mite allergens in Chinese patients with allergic rhinitis and asthma. Chin Med J (Engl) 2010, 123:3540-3544.

16. Cuesta C, Placido JL, Delgado L, Miranda M, Moreira Silva JP, Castel-Branco MG, Vaz M: Cockroach allergy: a study of its prevalence using skin tests with commercial extracts. Allergol Immunopathol (Madr) 1995, 23:295-300

17. Uzel A, Capan N, Canbakan S, Yurdakul AS, Dursun B: Evaluation of the relationship between cockroach sensitivity and house-dust-mite sensitivity in Turkish asthmatic patients. Respir Med 2005, 99:1032-1037.

18. Montealegre F, Meyer B, Chardon D, Vargas W, Zavala D, Hart B, Bayona M: Comparative prevalence of sensitization to common animal, plant and mould allergens in subjects with asthma, or atopic dermatitis and/or allergic rhinitis living in a tropical environment. Clin Exp Allergy 2004 34:51-58.

19. Santos $A B$, Chapman MD, Aalberse RC, Vailes LD, Ferriani VP, Oliver $C$, Rizzo MC, Naspitz CK, Arruda LK: Cockroach allergens and asthma in Brazil: identification of tropomyosin as a major allergen with potential cross-reactivity with mite and shrimp allergens. J Allergy Clin Immunol 1999, 104:329-337.

20. Shafique RH, Inam M, Ismail M, Chaudhary FR: Group 10 allergens (tropomyosins) from house-dust mites may cause covariation of sensitization to allergens from other invertebrates. Allergy Rhinol (Providence) 2012, 3:e74-e90.

21. Juliá-Serdá G, Cabrera-Navarro P, Acosta-Fernández O, Martín-Pérez $P$, García-Bello MA, Antó-Boqué J: Prevalence of Sensitization toBlomia tropicalisamong Young Adults in a Temperate Climate. J Asthma 2012, 49:349-354

doi:10.1186/1939-4551-7-22

Cite this article as: Pefura-Yone et al:: Sensitisation to Blattella germanica among adults with asthma in Yaounde, Cameroon: a cross-sectional study. World Allergy Organization Journal 2014 7:22

\section{Submit your next manuscript to BioMed Central and take full advantage of:}

- Convenient online submission

- Thorough peer review

- No space constraints or color figure charges

- Immediate publication on acceptance

- Inclusion in PubMed, CAS, Scopus and Google Scholar

- Research which is freely available for redistribution 